\title{
Nursing knowledge construction and occupational health
}

\author{
Maria Lúcia do Carmo Cruz Robazzi
}

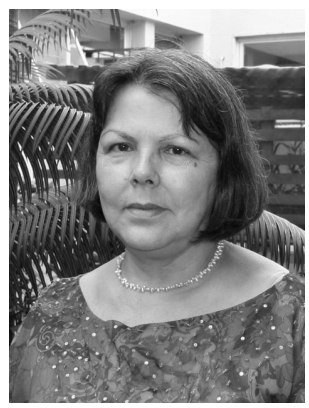

Occupational health is a necessary, complex and socially important scientific knowledge area. Studies address health and its relation with the pleasure and suffering of work.

In nursing, occupational health research shows a scenario that is predominantly focused on the occupational risk factors presents in the profession's own work environments, particularly highlighting studies on the profession's care practice, to the detriment of research on workers' health. Therefore, the work of nurses and nursing deserve further attention in research, due to the complex range of situations nursing professionals are confronted with, whose work is often performed in inappropriate conditions.

It is important to move beyond previously explored research areas, in search of others that can result in innovative studies, that is, there is a need to seek research problems that contribute ${ }^{(1)}$ to knowledge advances in this area. Moreover, research results need to apply to practice, with a view to improving the quality of life at work in the different professional activities that are part of each production chain.

Studies need to be expanded into hardly explored theme areas like child, slave, informal and elderly work, as well as the devalued activities performed by workers who remain "invisible", workers active in unhealthy/ dangerous locations, in slaughterhouses, tanneries, mineral extraction mines, rural work, workers handling chemical products, professionals with multiple jobs, among others.

In addition, some aspects of work that are more difficult to identify are underlined, related to the changes and mental suffering workers go through, depending on the work performed and its organization.

The Latin American Journal of Nursing has been publishing papers on occupational health and the different types of problems that can affect professionals in nursing and other areas. In this issues, some studies are published on moral suffering in daily nursing work, occupational health intervention in hospital nursing workers, occupational accidents among pre-hospital care workers and vaccination among Primary Health Care professionals.

\section{Reference}

1. Zanetti ML. Why is it difficult to publish in high-impact journals? Rev. Latino-Am. Enfermagem 2012;20(4):633-4.

Maria Lúcia do Carmo Cruz Robazzi is Associate Editor of the Revista Latino-Americana de Enfermagem, and Full Professor of the Escola de Enfermagem de Ribeirão Preto, Universidade de São Paulo, WHO Collaborating Centre for Nursing Research Development, SP, Brazil. E-mail: avrmlccr@eerp.usp.br. 